\title{
Challenges in the diagnosis of pheochromocytoma - a case report
}

\section{Aleksandra Zdrojowy-Wetna, Grażyna Bednarek-Tupikowska Department of Endocrinology, Diabetology and Isotope Therapy, Wrocław Medical University}

\section{Introduction}

Adrenal pheochromocytomas are rare neuroendocrine tumours, however their prevalence is probably underestimated - in some series $50 \%$ were diagnosed at autopsy. The clinical presentation varies among patients, that is why diagnosis might be delayed.

\section{Case report}

49-year old woman with hypertension was referred to the Endocrinology Department in Wrocław with suspected pheochromocytoma.

2002: operation of right carotid paraganglioma

2012: operation of left carotid paragangioma, complicated with stroke

- administration of anticoagulants

- bleeding from gastrointestinal tract

- CT of abdomen:

tumour in the right adrenal gland $6,5 \times 5,5 \times 4,3 \mathrm{~cm}$

tumour in left ovary $14 \times 18 \times 7 \mathrm{~cm}$

Clinical symptoms: uncontrolled hypertension with episodes of hypotension, weight loss (11 kg in 2 months), diabetes

Family history:

sister - caraotid paraganglioma father - cardiovascular disease ( $† 56 y r)$
Adrenaline in blood

Noradrenaline in blood

Adrenaline in urine

Noradrenaline in urine

Metoxycatecholamines in

urine

The patient was operated on January 2013 after administration of alfa- and beta-blokers.

Histopatological examination:

pheochromocytoma epinephri: IKi67 $(+)<1 \%$, synaptophysin $(+)$, chromogranin A (+), S100 (+), CD56(-), Melan A (-), alfa 1 inhibin (-), CD34 (-), Calretinin (-)

teratoma maturum cysticum ovarii

After removing pheochromocytoma most of the clinical symptoms subsided.
Genetic screening mutation in SDHD gene positive $\left({ }^{*}\right)$ Diagnosis: pheochromocytoma-paraganglioma syndrome

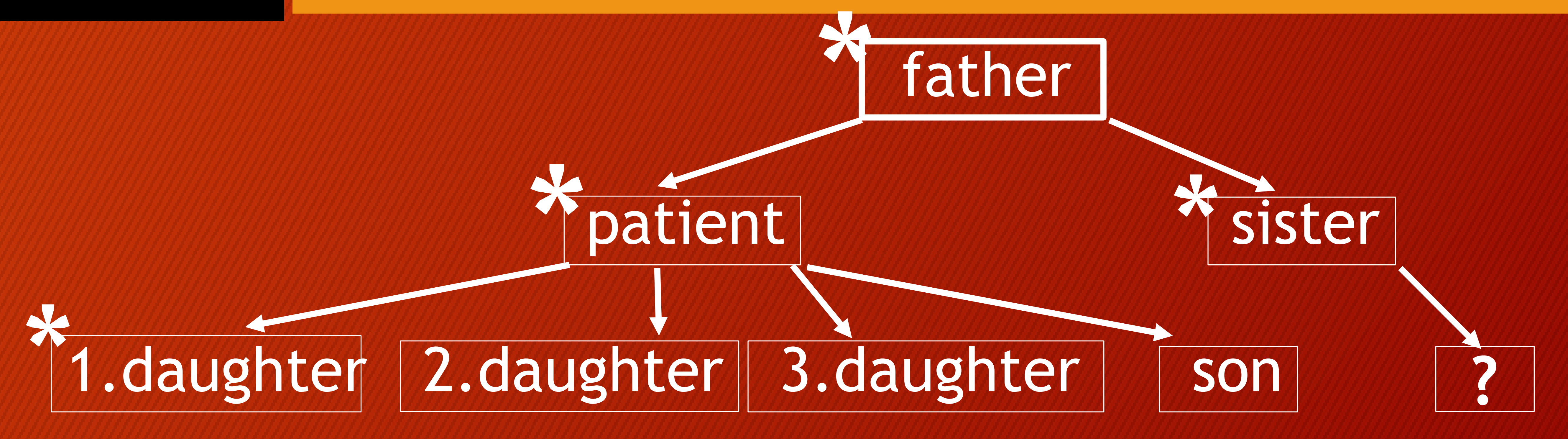

\section{Conclusions}

1. Occurrence of paraganglioma with hypertension suggest need of screening for pheochromocytomaparaganglioma syndrome, especially in case of paragangliomas in family history.

2. Early treatment is crucial to avoid life-threatening cardiovascular complications. 